\title{
Óscar Niemeyer e o seu novo nome, 40 anos depois
}

Manaira Aires Athayde Universidade de Coimbra / CAPES

erta vez chegou às mãos de Ruy Belo um catálogo
editorial a promover os livros que haviam sido
publicados naquele ano. Ruy Belo tentou encontrar na seção de poesia a sua mais recente obra, e já chateado por não vê-la na lista, logo percebeu que, afinal, ela estava incluída na bibliografia de livros de direito. Tratava-se de $O$ Problema da Habitação - Alguns Aspectos, cuja carga metafórica da palavra "habitação" gerou ainda um outro equívoco: o autor encontrou numa livraria o seu livro recém-publicado na seção de arquitetura.

A ironia que há nesses dois espisódios é que quem classificou a obra não se deu ao trabalho sequer de abri-la e perceber que se tratava de um livro de poesia, mas ao mesmo tempo a confiança que depositou apenas na análise do título para conduzir a escolha da categoria não foi de todo um engodo, afinal, é recursivo na obra beliana a acolhida a referências de diversas áreas e a ambiguidade no uso de termos. Estamos diante de um poeta pleno da intertextualidade e das interartes, que nunca escusou de colocar a sua poesia em contato com as mais diversas formas de arte. Com a arquitetura, podemos dizer que não há uma relação apenas temática, ou pautada por processos ecfrásticos ou por transposição narrativa, mas sobretudo uma relação situada no plano discursivo, na construção do discurso poético. 
«Óscar niemeyer» é um poema que revela essa tessitura. À referência explícita logo no título ao mais renomado arquiteto brasileiro do século XX junta-se a menção de várias de suas obras ao longo do poema, como o edifício da Editora Mondadori de Milão, o Ministério dos Negócios Estrangeiros da cidade de Argel, a cidade de Brasília, o Casino do Funchal, o edifício da Universidade Mentouri de Constantine, as casas para estudantes em Oxford, o conjunto urbanístico em Dieppe, o ateliê de Paris, na famosa Avenue des Champs-Élysées. Uma pessoa pouco atenta à leitura pode mesmo dizer que se trata de um poema em homenagem a Niemeyer (as "homenagens" eram muito frequentes naqueles tempos totalitários), poema este que eleva tais monumentos ao descrevê-los com um lirismo até bastante rebuscado (intencionalmente, claro) para o que costuma ser a "temperatura poética" de Ruy Belo.

Acontece que dentro de toda essa leitura declarada há vários óbvios invisíveis, a começar pela própria lista de obras mencionadas. Apenas uma construção vem sob o mote da metáfora absoluta, não sendo mencionada expressamente: estamos a falar da obra que "solta ao vento a fita de vidro e aço que esvoaça no bairro de la villette de paris". Trata-se, pois, da sede do Partido Comunista Francês, com o seu prédio cheio de curvas de vidro e aço inaugurado em 1971 na Praça Colonel Fabien, justamente no bairro de La Villette, em Paris. Aliás, é no ano em que aceita fazer esse projeto e começa a desenhá-lo, portanto em 1965, que Niemeyer decide morar em definitivo na capital francesa, uma vez que percebeu que o regime instaurado pelo golpe militar de 1964 não seria passageiro e que as condições de liberdade política e ideológica no Brasil só se agravavam - Niemeyer era comunista declarado e tinha ligações ao Partido Comunista da União Soviética, além de uma sólida amizade com Luís Carlos Prestes, o representante desse partido no Brasil. 
Ora, mais do que uma homenagem, o poema é uma comemoração, no sentido de "memorar com", pela capacidade do arquiteto de reafirmar o seu posicionamento ideológico em tempos onde se tinha pouco, muito pouco para se comemorar. Memorar com o leitor o conjunto da obra mas também o artista, a completude artística que Ruy Belo admirava em Niemeyer. Lembremos que o poema, datado de finais de agosto de 1973, foi escrito no mesmo ano em que o poeta lança Transporte no Tempo, livro cujo prefácio «Breve programa para uma iniciação ao canto» é um verdadeiro texto militante que circunscreve o que Belo pensa ser a postura do poeta (e que podemos estender para os artistas em geral) diante de seu tempo.

Para Ruy Belo, "escrever é desconcertar, perturbar e, em certa medida, agredir". Ele diz que os esforços são grandes para se institucionalizar o escritor: "acabarão por lhe encontrar coerência, evolução harmoniosa, enquadramento numa tradição". "Servir-se-ão dele, utilizá-lo-ão, homenageá-lo-ão". Sabem que assim o conseguirão "calar, amordaçar, reduzir". Mas que resistir deve ser a melhor maneira de o poeta denunciar-se e denunciar, introduzir "a intranquilidade nas consciências, nas correntes literárias e ideológicas, na ordem pública, nas organizações patrióticas ou nas patrióticas organizações".

Acomete-nos a ressalva, inclusive, de que no mesmo ano em que lança Transporte no Tempo (e escreve «Óscar niemeyer»), Ruy Belo publica a antologia pessoal País Possível, onde no prefácio lemos uma espécie de continuidade do texto inicial de TNT, só que agora centrado sobretudo nas condições da sociedade portuguesa naquele período. Nessas «Notas do Autor», refere-se a si como "um homem que sente na sua poesia a sua mais profunda razão de vida mas se sente, simultaneamente, solidário com os outros homens, que talvez tenham dificuldade em compreendê-lo porque houve quem se empenhasse em que não compreendessem". Afinal, para 
um "homem que nasceu livre e quer morrer livre", "pensar é realmente um perigo, o maior dos perigos". (Lembremos ainda que parte da poesia beliana amplamente avivada nos últimos anos está ligada à chamada "poesia de intervenção", e Ruy Belo tem até mesmo recebido a alcunha de "poeta urgente", detentor de uma obra que, ao atingir a universalidade, consegue nos fazer entender melhor não só os tempos de crise mas a crise dos tempos).

Assim, tanto num como noutro texto, Belo fala de um poeta (um artista) que tem que descer às ruas e sujar as mãos com os problemas de seu tempo, que tem que ter olhos postos no futuro, num amanhã em que acredita ser possível haver mais justiça, mais beleza. E justiça, beleza e futuro são três palavras caras ao poeta em "Óscar niemeyer», palavras confiscadas, aliás, por "dias fortificados e relvados da idade média". Niemeyer e a sua "grandeza há uns nove anos comprimida no brasil" por "organismos de uma nova inquisição" que "lhe sonegam o espaço exigido por esse traço". Ruy Belo fala da ditadura brasileira com a propriedade de poeta que viu muitos outros escritores e artistas também serem podados por regimes totalitários. O próprio poema «Óscar niemeyer», que integra o livro de 1976, Toda a Terra, só foi publicado três anos depois de ter sido escrito, quando já havia ocorrido o « 25 de Abril» com a Revolução dos Cravos em 1974, que colocou fim ao Estado Novo. Não por acaso ainda no prefácio de País Possível Ruy Belo se refere a uma sociedade que permite que o poeta se vá "suicidando lentamente porque essa sociedade o destrói e assassina e o censura e a censura se instala na sua própria consciência".

Não olvidemos, inclusive, que a ida de Ruy Belo para Madrid, em 1971, onde foi leitor da Universidad Complutense de Madrid por seis anos, deveu-se em grande parte por estar cansado de ter as suas atividades vigiadas pela Polícia 
Internacional e de Defesa do Estado, conhecida como PIDE. No Arquivo Nacional Torre do Tombo, em Lisboa, é possível encontrar documentos da PIDE referentes a Ruy Belo, que passou a ser monitorado sobretudo pelo seu relacionamento com opositores ao regime, bem como por ter em seu histórico a participação na greve acadêmica de 1962 e se candidatar a deputado, em 1969, pelas listas da Comissão Eleitoral de Unidade Democrática, acabando então por não ser eleito. Quando escreve o poema Quando escreve o poema «Óscar niemeyer» nas férias de verão de 1973, na Praia da Consolação, já estava a viver em Madrid há quase dois anos, tendo assim vivenciado tanto o regime salazarista quanto o franquista.

Embora nessa altura os dois governos ditatoriais já estivessem em suas fases de declínio (a ditadura em Portugal chegaria ao fim um ano depois e, na Espanha, passados três anos), no Brasil vivia-se um período que ficou conhecido como «anos de chumbo", marcado pelo exponencial aumento da censura e da repressão, com o governo de Emílio Garrastazu Médici a usufruir de todos os poderes extraordinários que o Ato Institucional No 5, ou AI-5, havia facultado em 1968, suspendendo várias garantias constitucionais e permitindo inclusive o fechamento do Congresso Nacional.

No entanto, é uma época que também suscita importantes reflexões sobre a relevância do ativismo a partir de críticas sociais e manifestações políticas nas mais diversas intervenções artísticas, sem que se comprometesse, todavia, o compromisso estético da arte como plano primeiro, conforme enunciava Ruy Belo. Diga-se mesmo do seu interesse pelo trabalho de vários artistas brasileiros no que toca ao debate sobre o posicionamento ideológico do artista e o papel sociológico da arte, e dentre as principais referências para o poeta encontramos não só Óscar Niemeyer na arquitetura, mas Chico Buarque na música e Glauber Rocha no cinema. 
A propósito, conta a professora universitária María Victoria Navas, na altura aluna de Ruy Belo no leitorado de português da Universidad Complutense de Madrid, que no primeiro dia de aula ele colocou a turma para ouvir e fazer uma análise da música de Chico Buarque "Construção», de modo que rapidamente os alunos perceberam que se tratava de um professor "diferente", que os instigava a pensar sobre as condições políticas e sociais em que viviam. Também foi em Madrid, logo quando se mudou para a capital espanhola e passou a morar na residência universitária Casa do Brasil, que Ruy Belo tomou conhecimento de filmes de Glauber Rocha como Deus e o Diabo na Terra do Sol, de 1963, e Terra em Transe, de 1967. Está datado por Ruy Belo a 30 de maio de 1973 o livro Glauber Rocha - Revision Critica del Cine Brasileño, onde ao folhear as suas páginas ainda encontramos a ficha de encomenda do livro, feita a Libreria Universitas, o que demonstra o interesse do poeta pela obra, não se tratando de uma aquisição meramente casual.

E contingência é algo que não parece haver de forma alguma nessas relações intertextuais de Ruy Belo, como nos mostra o próprio poema «Óscar niemeyer». Exatos 40 anos depois de ter sido escrito, voltamos a esse poema para comemorar as tantas homenagens que há nele. Homenagens a artistas como Óscar Niemeyer, Chico Buarque, Glauber Rocha e tantos outros que, mais do que serem contrários a regimes totalitários, foram antes de tudo a favor, como o próprio Ruy Belo o foi, de um hino expresso com apenas uma palavra. Uma palavra implícita ao longo de todo o poema «Óscar niemeyer», que onde se lê "Niemeyer mudou de nome e chama-se agora somente arquitectura" talvez se preferisse dizer "Niemeyer mudou de nome e chama-se agora somente liberdade". Liberdade, nome e sobrenome da arquitetura de linhas curvas de Niemeyer. Liberdade, "arte arejada palavra de betão proferida dos telhados mais altos da idade futura", como lemos no último verso. 


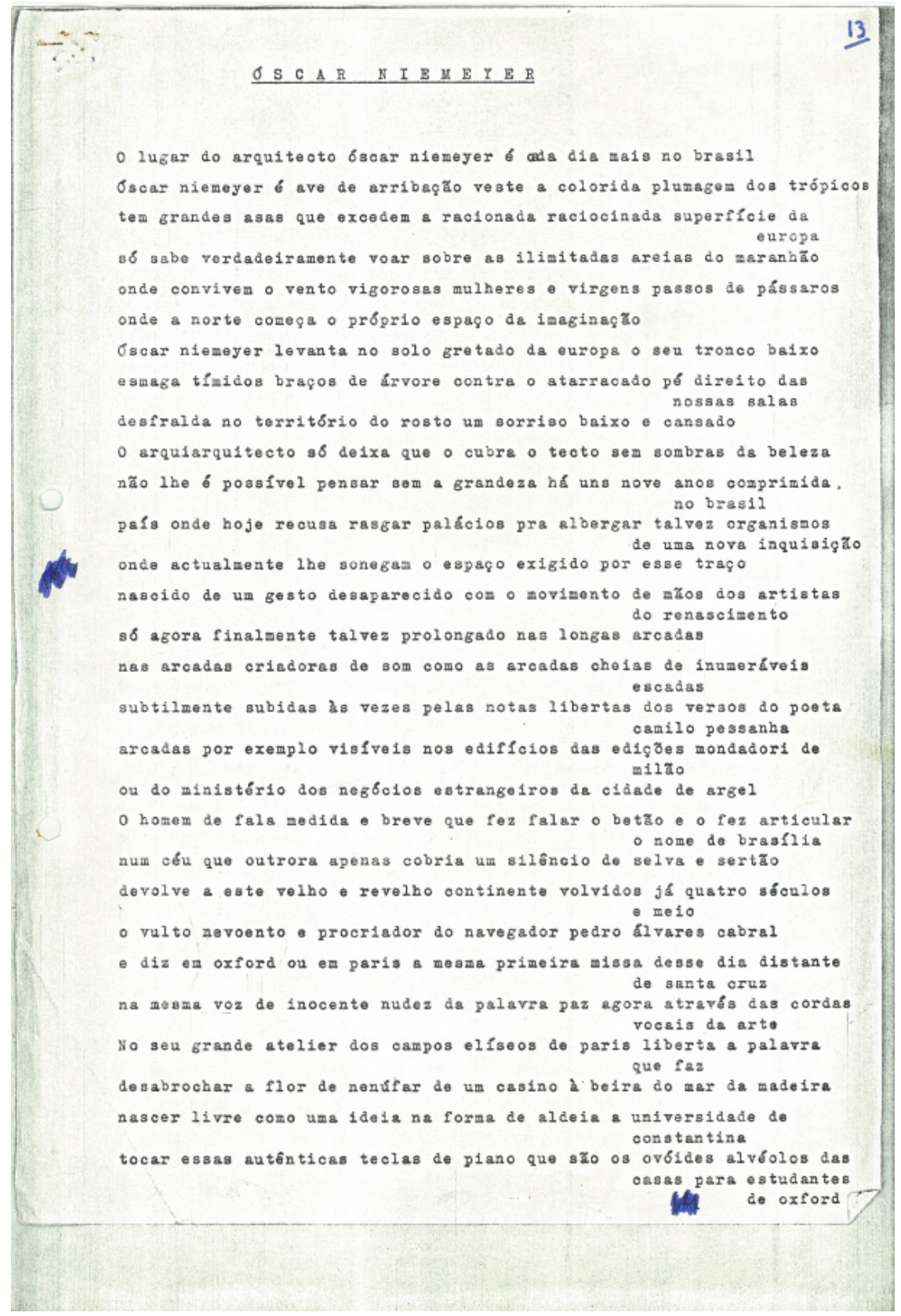




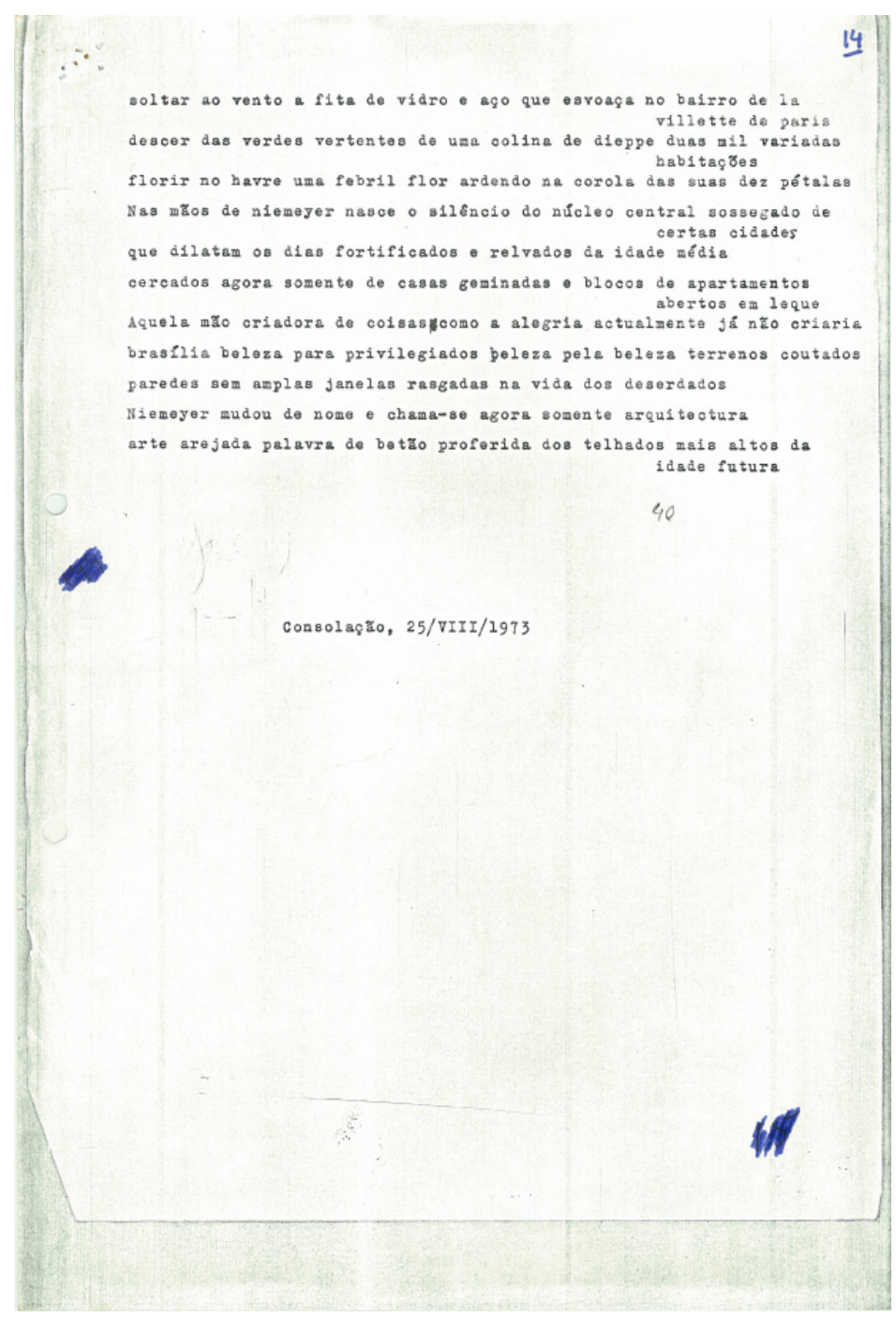

Fac-símile do datiloscrito, até então inédito. O poema «Óscar niemeyer» integra o livro Toda a Terra (1976), editado este ano no Brasil pela 7Letras, num projeto iniciado que prevê a publicação da obra completa do autor livro a livro. 